\title{
Programme for health and social affairs
}

Swedish Presidency 2018

111.) Nordic Council of Ministers 
Programme for health and social affairs

Swedish Presidency 2018 of the Nordic Council of Ministers

ANP 2017:796

ISBN 978-92-893-5319-9 (PRINT)

ISBN 978-92-893-5320-5 (PDF)

ISBN 978-92-893-5321-2 (EPUB)

http://dx.doi.org/10.6027/ANP2017-796

(C) Nordic Council of Ministers 2017

Layout: Louise Jeppesen

Cover Photo: unsplash.com

\section{Nordic co-operation}

Nordic co-operation is one of the world's most extensive forms of regional collaboration, involving Denmark, Finland, Iceland, Norway, Sweden, the Faroe Islands, Greenland, and Åland.

Nordic co-operation has firm traditions in politics, the economy, and culture. It plays an important role in European and international collaboration, and aims at creating a strong Nordic community in a strong Europe.

Nordic co-operation seeks to safeguard Nordic and regional interests and principles in the global community. Shared Nordic values help the region solidify its position as one of the world's most innovative and competitive. Nordic Council of Ministers.

\section{Nordens Hus}

Ved Stranden 18

1061 København K www.norden.org

Download Nordic publications at www.norden.org/nordpub 


\title{
Programme for health and social affairs
}

\author{
Swedish Presidency 2018 of \\ the Nordic Council of Minjsters
}

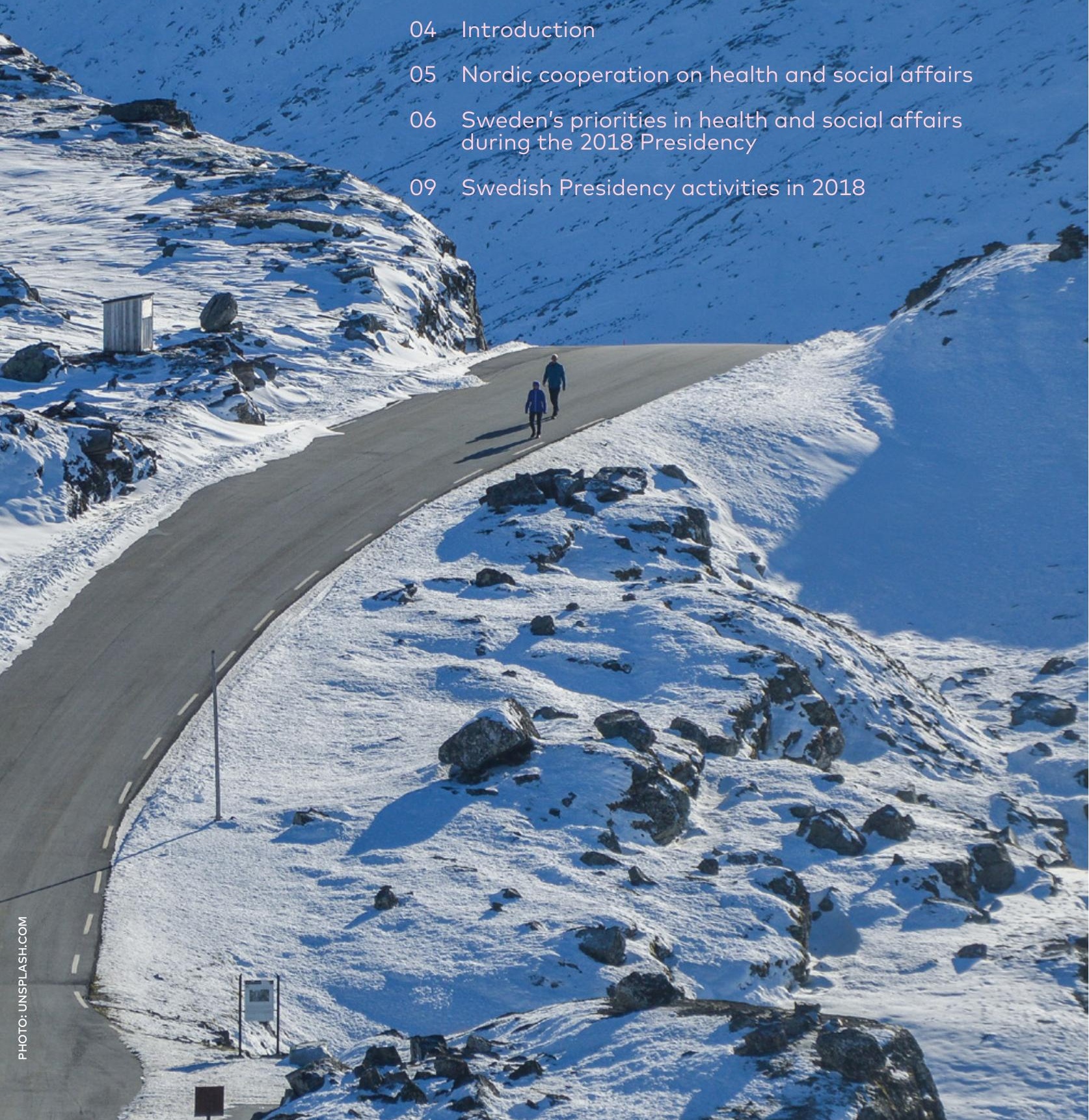


In 2018, Sweden will hold the Presidency of the Nordic Council of Ministers (NCM). The starting point for Sweden's Presidency is an inclusive, sustainable, innovative and safe Nordic region, with digital transformation as the common theme. In the sectoral programme for health and social affairs, Sweden's Presidency will particularly focus activities on the theme of elderly people and an ageing population, including the challenges involved for medical care and social services.

Gender equality is taken into account in all activities that can contribute to the gender equality policy objective on gender-equal health. In addition, the Nordic Committee for Senior Officials and the Nordic Council of Ministers will focus on developing cooperation in the social policy area. 


\section{Nordic co-operation on health and social affairs}

The Nordic governments' cooperation on health and social affairs is led by the Nordic Council of Minister for Health and Social Affairs (MR-S). This cooperation is based on the Nordic countries' common values, which form the basis of the Nordic welfare model. Nordic cooperation in the health and social affairs sector is also significant for achieving the UN's Global Goals in the 2030 Agenda.

The principles of the welfare society in the Nordic region are based on citizens' equal opportunities and social solidarity and security for everyone, regardless of sex, ethnicity, religion, belief, disability, age or sexual orientation. In practice, it is a question of social rights and everyone having equal access to health and medical services, social services, education and culture. This also applies to care for socially vulnerable people and groups in society.
The Nordic co-operation programme for health and social affairs for 2017-2020 focuses on four specific objectives for strengthened sustainable welfare and health in the Nordic region:

- Promoting welfare and health policy that ensures social security in a changing labour market and includes vulnerable groups, and prevents social exclusion.

- Promoting a goal-oriented and efficient input of resources in health and social affairs that meets future needs to a greater extent. Preventive, early initiatives and rehabilitation will be given priority.

- Raising the level of quality and security in health and medical care, social and welfare services.

- Promoting innovation and research on the health, social and welfare services of the future. 


\section{Sweden's priorities in health and social affairs during the 2018 Presidency}

Based on these long-term objectives, the 2018 Swedish Presidency of the Nordic Council of Ministers for Health and Social Affairs has chosen to give priority in its programme to the following themes and activities:

\section{Quality in elderly care and a better working environment}

One example of activity in the focus area 'elderly care' is the conference on the theme Working in elderly care which will be held during the year. Part of the objective is to emphasise and highlight shortcomings in the working environment, such as stress and heavy workloads for staff. However, the primary objective is to inspire and demonstrate change that can lead to a better working environment, make the profession more attractive, and increase well-being and health among staff and, thereby, also the quality of social elderly care.

\section{Presidency project for innovative} service solutions and remote health care The Nordic countries face common challenges in the form of an ageing population and increasingly depopulated rural areas, which means it is likely that the need for remote solutions in health and social care will increase in the future.

This is why it is important to make use of the potential that exists in the Nordic region and counteract increased regional imbalance, while promoting economic growth, population development and services. Innovative service solutions and models are needed to handle demographic challenges based on the regions' and communities' various conditions, particularly in rural areas. New ways of delivering welfare services is one possibility. However, remote solutions for health and social care must be seen as a complement and not as a replacement for physical contact with these services.

Within Nordic cooperation, the country holding the Presidency has access to a Nordic budget to initiate and conduct particularly prioritised activities. One of four such major projects that Sweden will launch in 2018 is Advanced solutions for remote health care and ePrescriptions across national borders, with a budget of DKK 12 million distributed over three years. 


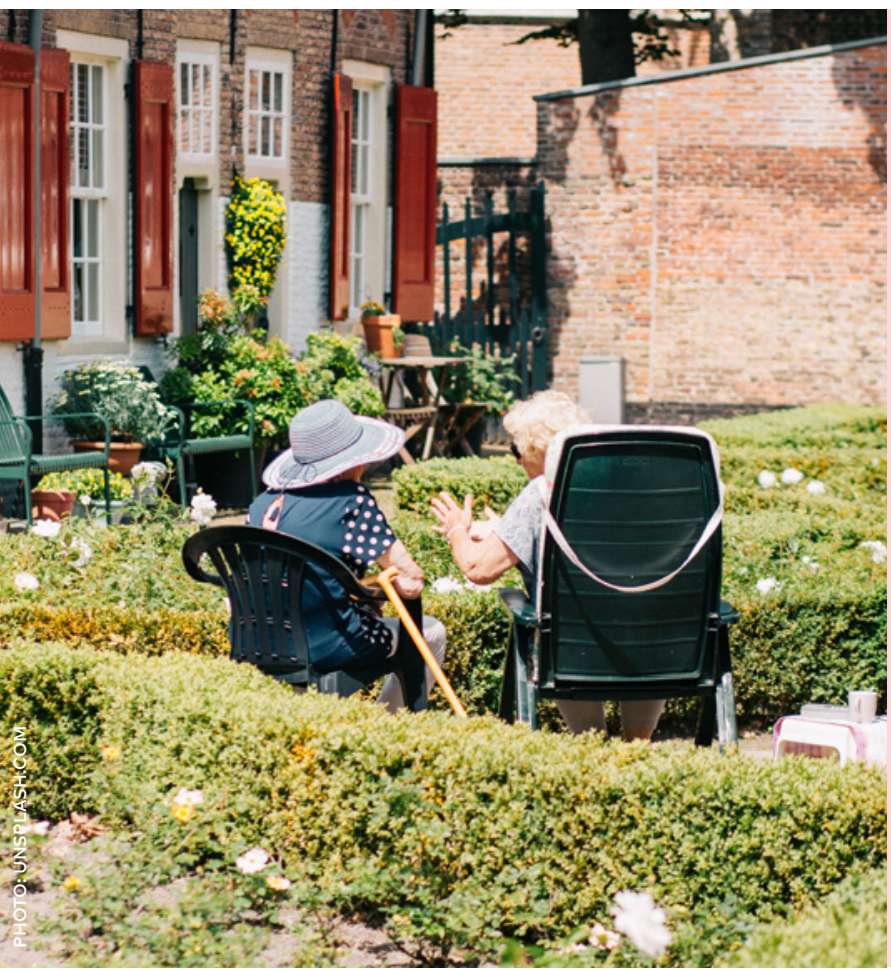

Cooperation in the Nordic Council of Ministers aims to promote mobility between the Nordic countries and develop the Nordic welfare society in a European perspective. Further, efforts are focused on developing the Nordic region's cooperation with its neighbourhood and exchanging experiences and national information. Nordic benefit is a fundamental principle of the cooperation.

A sub-target of the project is to have the technical requirements in place within three years for the exchange of ePrescriptions in the Nordic region.

\section{Review of social affairs}

In March 2017, the Nordic health and social affairs ministers in the MR-S decided to ask the Secretary General to carry out a strategic review of Nordic cooperation in the social affairs area. This is after an earlier, corresponding review had been carried out with a focus on Nordic cooperation in the health area. The objective of the new review is to develop and enhance cooperation on social affairs in a way that is adapted to the countries' needs and current problems, and to ensure that it leads to tangible results. The idea is that the review is to have a starting point in and develop the Nordic welfare model and focus on whether investments in social activities and services can help meet social challenges. The results will be presented during the Swedish Presidency following discussions at the Nordic health and social affairs ministers' meeting in March 2018. Sweden's Presidency work will then include organising and realising Nordic cooperation on proposals that emerge in the final report of the review. 


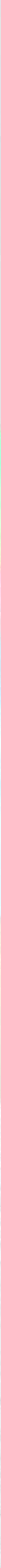




\section{Swedish Presidency activities in 2018}

In 2018, updated information on Presidency activities will

be regularly published on www.regeringen.se/norden.

\section{MEETINGS IN THE COUNCIL FOR MINISTERS FOR HEALTH AND SOCIAL AFFAIRS (MR-S) AND SECRETARIAT FOR THE NORDIC COMMITTEE OF SENIOR OFFICIALS FOR HEALTH AND SOCIAL AFFAIRS (ÄK-S)}

9 February ÄK-S (1) gathers for its first meeting of the year

On 14 February, the evening prior to the meeting, the 2018

Swedish Presidency in the Nordic Council of Ministers will host a reception at the Swedish Embassy in Copenhagen for the ÄK-S delegations and the Secretariat to the Nordic Council of Ministers. And thereafter a networking dinner. The adresses and time will be announced in the ÄK-S meeting invitation.

Venve: Copenhagen

22 March

MR-S gathers for its annual meeting

Venue: Uppsala

14-15 June

ÄK-S (2) gathers for its second meeting of the year

Venue: Ystad

15-16 November

ÄK-S (3) gathers for its third meeting of the year

Venue: Gothenburg region 


\section{PROJECTS, MEETINGS, SEMINARS AND CONFERENCES}

March/April

20 April

\section{High-level meeting for Nordic heads of ministry or department in health care}

Between 2018 and 2020, annual high-level meetings will he held with the objective of developing the network and strengthening the dialogue between the most senior managers in health and social affairs at the national ministries. This will be the first meeting for managers in health care.

Venve: Stockholm region

\section{Working in elderly care}

Conference on working environment, quality and gender equality in elderly care.

The most important resource in elderly care is the staff, of whom 90 per cent are women. Deficiencies such as stress, a heavy workload and too little access to managers lead many people to want to quit, high sick leave rates and difficulties for municipalities to recruit and retain staff.

The objective of the conference is to highlight existing problems and to show various ways of supporting positive development. The conference will target decision-makers at national, regional and local level, government agencies, municipal and regional associations, and professional, pensioner and user representatives.

Venve: Stockholm 
Transforming healthcare and social services A conference on how the demographic challenges of ageing populations increase the need for health and social care in the Nordic countries, and how innovation and organisational changes can be part of the arsenal of measures to meet growing needs.

Demographic projections will be created using modern information technology and concepts such as eHealth and remote health will be addressed. The nationalisation of Norwegian hospitals in the early 2000s will be reviewed and implemented Danish municipal and regional reforms will be presented. A planned Finnish reform throughout the health and social care sector will be featured, and there will be opportunities for conference participants to exchange experiences.

Venue: Malmö
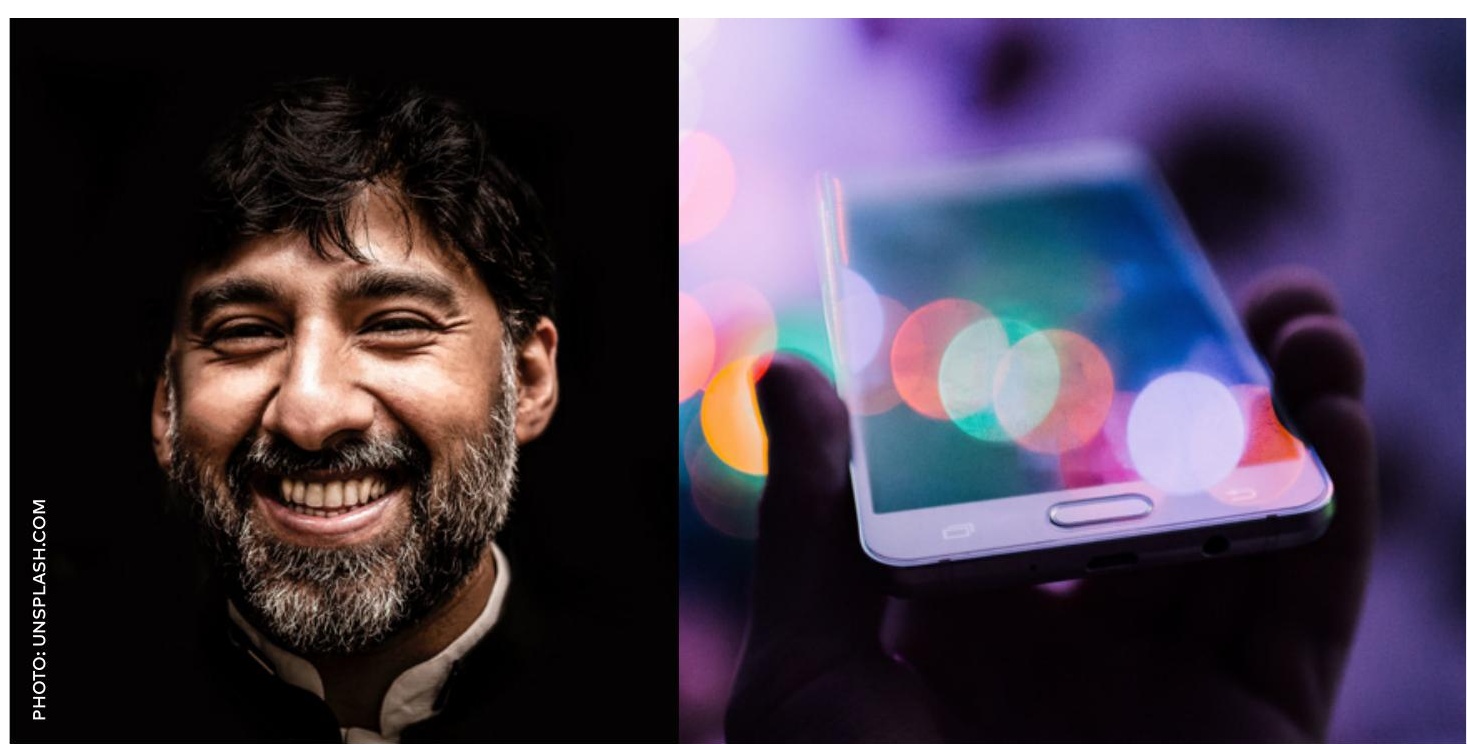
Activity on Nordic comparative study:

The Nordic pension gaps -

gender-equal pensions

Unequal labour force participation and differing salary levels between men and women lead to disparities in income between the sexes in working life. An earnings pension system based on own earnings propagates inequality in retirement through unequal pensions. This is, essentially, a structural problem during working life, but measures can be taken to close the gap.

During its Presidency, Sweden will initiate a Nordic study to form the basis for continued work on gender-equal pensions in the Nordic region. The objective will be to: - discuss a future common standard for estimating and comparing the pension gap in the Nordic countries with a possibility to monitor these over time;

- exchange experiences and ideas on measures to close the gap;

- gain a greater focus and attention on the issue and stimulate improvements; and

- generate greater pressure to measure the gap and actions to close it.

Venue: Stockholm 
November

\section{Nordic eHealth meetings}

The Nordic countries' health and medical care systems have many basic similarities. eHealth is an area that has been discussed at different levels for a number of years. All Nordic countries apply different measures, and this meeting will be an opportunity to meet and discuss current issues in a Nordic context. The proposal is for meetings to be held at several locations around the country over the course of one week to include various regional actors who are involved in the prioritisation project on remote health care and ePrescriptions, such as Glesbygdsmedicinskt centrum in Storuman.

Venve: Stockholm and one or two additional locations

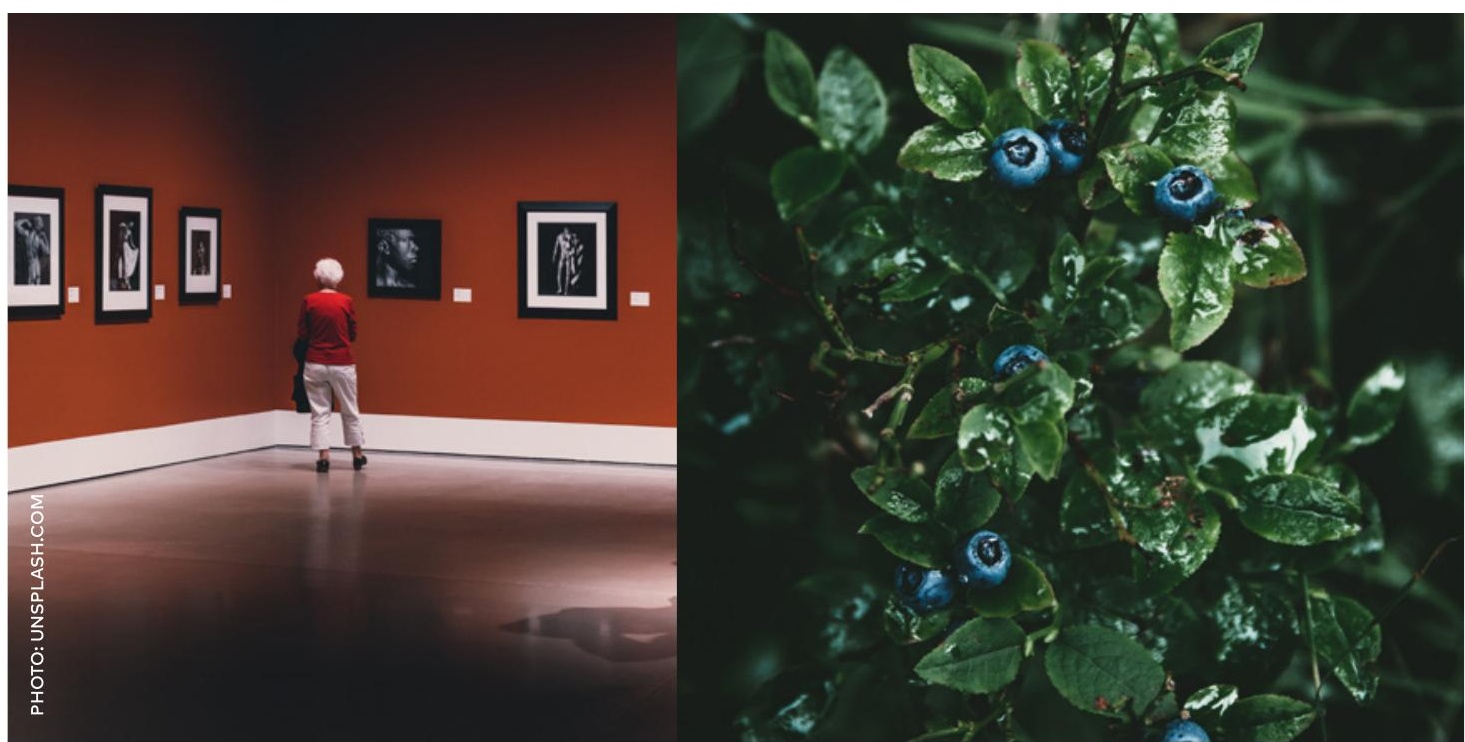




\section{ACTIVITIES AND PROJECTS THAT WILL ADDITIONALLY BE CARRIED OUT IN AUTUMN 2018}

Start-up of projects on a Nordic network for age-friendly cities An initiative under Sweden's Presidency in 2018 in collaboration with the World Health Organisation (WHO), the Nordic Welfare Centre (NVC) and the Secretariat to the Nordic Council of Ministers to organise a start-up conference with the objective of developing a Nordic network activity on age-friendly cities under the WHO Global Network for Age-friendly Cities and Communities, in which some 350 cities in the world are working together.

Venue: Stockholm

\section{Activity with the Nordic Welfare Centre}

Activities or

resources in 2018 regarding public health/gender-equal health in connection with the Nordic Welfare Centre's overarching event in the autumn to present the Public Health Arena's activities and projects. 
Nordic Council of Ministers

Nordens Hus

Ved Stranden 18

1061 København $\mathrm{K}$

www.norden.org

ANP 2017:796

ISBN 978-92-893-5319-9 (PRINT)

ISBN 978-92-893-5320-5 (PDF)

ISBN 978-92-893-5321-2 (EPUB) 